\title{
Teaching Early Literacy, Mathematics, and Patterning to Kindergartners
}

\author{
Robert Pasnak*, Katrina Gagliano, Matthew Righi, Julie K. Kidd \\ Department of Psychology, George Mason University, Fairfax, VA, USA \\ Email: *rpasnak@gmu.edu
}

How to cite this paper: Pasnak, R., Gagliano, K., Righi, M., \& Kidd, J. K. (2019). Teaching Early Literacy, Mathematics, and Patterning to Kindergartners. Psychology, 10, 1493-1505.

https://doi.org/10.4236/psych.2019.1011098

Received: July 9, 2019

Accepted: August 20, 2019

Published: August 23, 2019

Copyright $\odot 2019$ by author(s) and Scientific Research Publishing Inc. This work is licensed under the Creative Commons Attribution International License (CC BY 4.0).

http://creativecommons.org/licenses/by/4.0/

\section{(c) (i) Open Access}

\begin{abstract}
The effects of instructing kindergarten students (five-year-old in their first year of public school) on patterning were tested. Up to nine students in each class were randomly assigned to three groups in each of six classes, i.e., as many as three from a class in each group. One group received instruction on complex patterns similar to those employed by other researchers with first graders. Another group was instructed in early literacy, and another in early mathematics. For each group, the experimental instruction was scheduled in a counterbalanced order for 15 minutes in the morning, five days per week for most of the school year. When tested in late May-early June, the children taught patterning scored significantly better on a test of patterning. There were no significant differences on tests of mathematics and early literacy. However, there were correlations between the children's patterning scores and some literacy scales.
\end{abstract}

\section{Keywords}

Kindergarten, Literacy, Mathematics, Patterning

\section{Introduction}

Instruction of preschoolers in "patterning" has been a staple of early education in some English-speaking countries for half a century. In the USA, it has been part of the Common Core for public education (Common Core) and has been recommended by professional organizations (National Council of Teachers of Mathematics or NCTM, 1993; NCTM /National Association for the Education of Young Children (2010/2014)). This form of instruction, termed "patterning", typically consists of teaching children to recognize repeating patterns in which the elements alternate, e.g., $\mathrm{ABABAB}$ or $\mathrm{ABB} A B B$ or $\mathrm{AABAAB}$ or $\mathrm{AABBAABB}$. Sometimes patterns have three elements (ABCABC). The patterns usually con- 
sist of small objects which alternate in color, size, shape, or type of object, or of similar graphicsor drawings. Instructional manuals exist (Ducolon, 2000; Jarboe \& Sattler, 2003) but in any event the instruction is relatively easy for any adult to carry out.

Patterning instruction has been incorporated in formal curricula (Building Blocks, Sarama \& Clements, 2004; PASMAP, Mulligan, Mitchelmore, Kemp, Marston, \& Highfield, 2008) and in many curricula developed by school districts. Instruction in patterning has been questioned (National Mathematics Advisory Panel, 2008) because children from countries where such patterns are not taught often do very well in early mathematics, and patterning is no longer part of the Common Core of American education. There is nevertheless empirical evidence from a longitudinal correlational study (Rittle-Johnson, Fyfe, Hofer, \& Farren (2017)) that there are significant relations between preschoolers understanding of patterns and their mathematics achievement, extending to fifth grade, and Rittle-Johnson, Hofer, Fyfe, \& Farren (2015) found similar relations between children's understanding of patterning at age 7 and mathematics measures at age 11 .

The incorporation of patterning into early education was for half a century based primarily on cogent reasoning advanced by educators, who suggested that it was likely to be important in early mathematics. Thus, to a young child, collections of shapes, patterns, or other items may seem to be idiosyncratic and not understandable in terms of any organizing principle or relationship. Learning that there ARE predictable patterns, in some cases, may be the initial step in understanding relations between items (Scandura, 1971; Clements \& Sarama, 2007a). The search for simple relations that make apparently random groups of objects or symbols predictable is the beginning of what is termed prealgebra. Patterning instruction can help children develop an important insight-that there is a common rule, such as alternation, that relates series of items that differ concretely, and subsequently that there are rules that make different numerical symbols predictable from one another. Articulating such rules is an essential part of early mathematics (McGarvey, 2012). Indeed, counting by fives produces alternating fives and zeroes (Economopoulos, 1998), and the decimal system of tens, which children learn early, is essentially a pattern (Clements, Sarama, \& Dibiase, 2004).

Understanding alternating patterns requires discrimination of differences and similarities in the items that make up the pattern (Papic, 2007), and when the alternation rule is abstracted, and applied to many kinds of items it has become a variable in itself (Threlfall, 1999), which children sometimes name (Baroody, 1993). Such reasoning has supported a consensus of educators that teaching children alternating patterns at the onset of schooling will facilitate their understanding of early mathematics. There have also been suggestions that early literacy may be improved by improving children's ability to recognize relationships through instruction in patterning (Sarama \& Clements, 2004). 
In some respects the theorizing and speculating about what patterning may contribute to educational achievement outraced the empirical evidence that it contributes anything. Until very recently, there was a dearth of empirical studies. For many years, the only evidence that instruction on alternating patterns improved children's performance in mathematics was an unpublished dissertation (Herman, 1973). That researcher found a small but significant difference between experimental children given rather extensive patterning instruction and control children on the Metropolitan Readiness Test. However, the control children came from another school, which suggest an alternative explanation. A study of preschoolers by Papic, Mulligan, \& Mitchelmore (2011) had the same limitation. There are substantial practical difficulties in assigning children to conditions randomly when they are enrolled in educational programs.

First Hendricks, Trueblood, \& Pasnak (2006) and then Kidd et al. (2013), Kidd et al. (2014), and Pasnak et al. (2015) were able to solve this problem by assigning first graders randomly to experimental and control groups. All of these studies showed that patterning instruction produced gains in mathematics, and all but that of Kidd et al. (2013) showed gains on standardized measures of reading. Hence, the utility of patterning instruction for first graders seems clear. However, these studies did not involve alternating patterns; instead, ascending and descending patterns of letters, numbers, and clock faces, and objects rotating through a sequence of positions were employed, and first graders have a more advanced understanding of such subject matter than do kindergartners or preschoolers. Patterning instruction is most often offered to preschoolers or kindergartners. Whether the form of patterning instruction tested with first graders would be as effective for younger children, or have any effect at all or even be practical is an open question. The current experiment was an effort to test this possibility.

\section{Method}

\subsection{Participants}

Informed consent was obtained for 64 kindergarteners enrolled in seven classes in a Virginia public elementary school. These kindergarteners were administered a two-part patterning test in the beginning of the school year (September or October). Children were subsequently randomly assigned to the patterning or literacy or mathematics conditions with the restriction that no more than three children per class be in each condition (because the procedures could not be effectively used with more than three children at one time.) After attrition-one teacher withdrew her class and the families of other children moved-the final sample consisted of 14 children in the patterning condition, 13 in the math condition, and 15 in the literacy condition. Demographics for this school were 54\% boys, $46 \%$ girls; $71 \%$ eligible for free or reduced cost lunches. Ethnicities were American Indian/Alaskan 2\%, Asian/Pacific Islander 8\%, African-American $35 \%$, Hispanic/Latino $31 \%$, White $22 \%$, and other $2 \%$. Birthdays were protected information and therefore not available. 


\subsection{Measures}

\subsubsection{Patterning Pre- and Posttest}

A 40 problem patterning test was used both at the beginning and end of the academic year. The patterning test had two parts. Part one contained six "skip 1" and six "skip 2" letter, clock, and number patterns (e.g., MOQSU or CFILO), and four rotation patterns (objects rotated in 90 or 135 degree steps). The patterns were presented in counterbalanced order, and in both vertical and horizontal orientations. Part two contained eight growing letter, number, clock, and shape patterns, (e.g, AKAKKAKKK), and eightsymmetric letters, numbers, clocks, and shapes patterns, (e.g. disc square oval oval square disc). There were also eight object or shape problems in which an object or shape was missing its right or left half. Again, all were presented in counterbalanced order and in both vertical and horizontal orientations. See Figure 1 for examples.

\subsubsection{KEYMath-3 Diagnostic Assessment}

The Algebra subtest of the KEYMath-3 Diagnostic Assessment was used to measure mathematical knowledge for participants. The Algebra subtest involves addition, patterns of different types than those taught in the patterning intervention, matching equations such that the total of two separate equations would be equal, and creating algebraic equations to match a scenario presented.

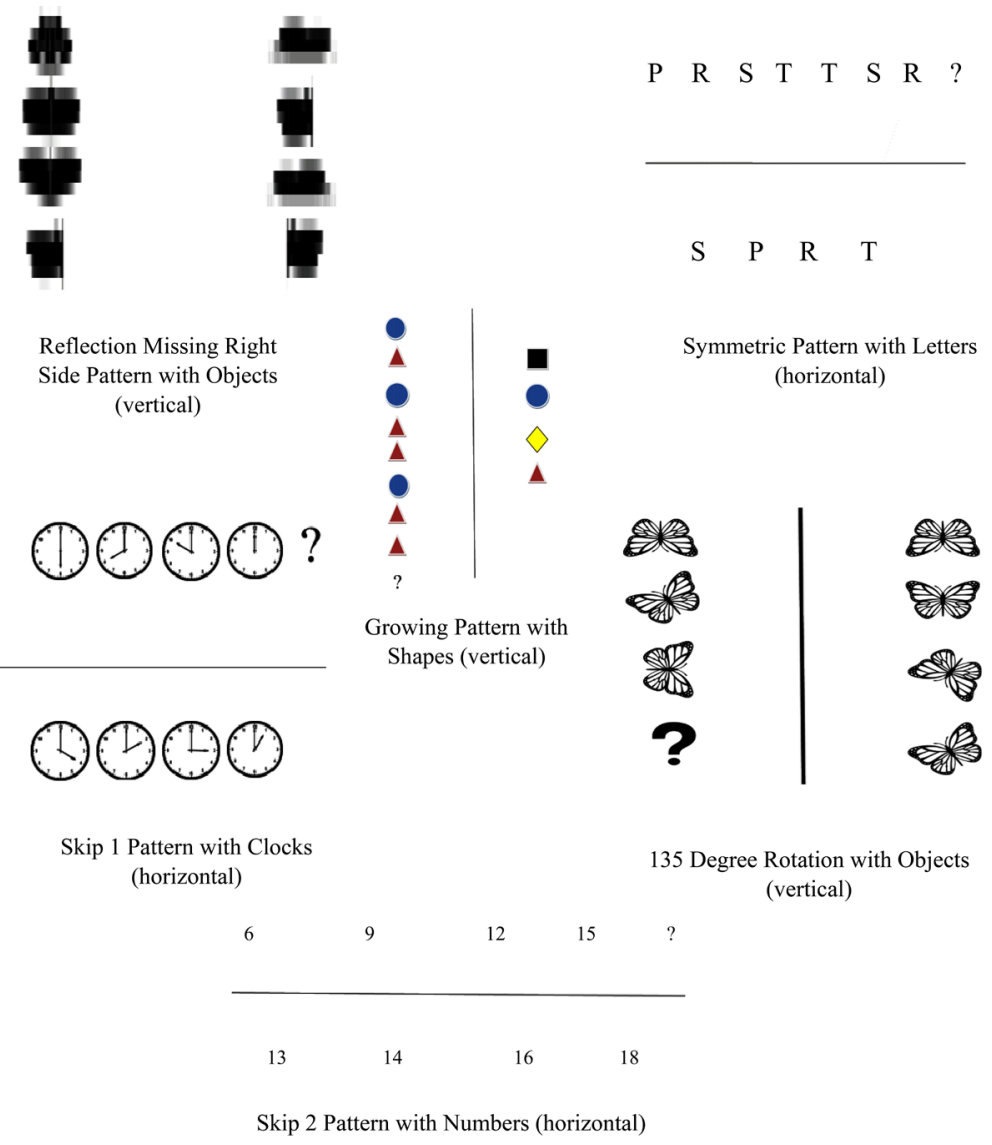

Figure 1. Examples of the types of patterns employed. 


\subsubsection{Test of Reading Word Efficiency (TOWRE)}

The TOWRE was used to measure word and phoneme reading. The TOWRE has two subtests: the Sight Word Efficiency (SWE) scale and the, Phonetic Decoding Efficiency (PDE) scale. The first is used to assess the number of real words a child could identify in 45 seconds and the second is used to measure the number of non-words a child could decode within 45 seconds.

\subsubsection{Dynamic Indicators of Basic Early Literacy Skills (DIBELS) $6^{\text {th }}$ Edition}

The DIBELS Initial Sound Fluency (ISF) measure was used to assess the children's ability to identify and produce the initial sound in a spoken word. The examiner presents four pictures to the child, then asks the child to point to a picture that begins with a specific beginning sound. After the child points to the picture, the child is asked to produce the beginning sound for the word that matches one of the pictures. The examiner calculates the time taken to identify and produce the correct sounds and converts this into a score of number of initial sounds correct per minute. The ISF took about three minutes to administer per child.

The DIBELS Nonsense Word Fluency (NWF) measure was used to assess the child's ability to understand that letters typically represent their most common sounds, and these sounds can be blended to create words, even if these words are not typically encountered in the English language. Children are presented a page filled with nonsense words and asked to vocalize the individual sounds in each word or to read the whole word. To obtain a correct score for three sounds in a word, the student must either say the word (i.e. /pov/) or say the sounds in the word separately (i.e. $/ \mathrm{p} / / \mathrm{o} / / \mathrm{v} /$ ). The examiner counts the number of correct letter-sounds produced in one minute. If students are reading whole words instead of each sound separately, they will receive a higher score because they will be more efficient in producing the letter sounds and therefore will complete more words in the allotted time. The NWF takes about two minutes to administer per child.

The DIBELS Letter Naming Fluency (LNF) measure was used to assess the child's ability to identify letters. Children are given a page with upper- and lower-case letters unsystematically arranged on it and are asked to name as many letters as they can in one minute. If the child comes across a letter he/she cannot name, the examiner provides the name of the letter. Examiners record the total number of letters identified by the child in one minute.

\subsection{Intervention Materials}

Intervention materials included a binder of graphic patterns for the patterning group; letter blend bags, ending sound flipcharts, and poems for the reading group; and math activities and supplies including coins, manipulatives, number cards, bingo cards and makers, and other small objects for the mathematics intervention group. Intervention materials are described in greater detail within the procedure below. 


\subsection{Procedure}

Undergraduate research assistants (RAs) assisted kindergarten teachers in the classroom and spent one hour per day either testing or conducting the intervention with the assigned children. At the start of the school year, after having one week in the classroom to get to know the children, RAs administered the patterning pretest for all children for whom parental consent was received. After the restricted randomization of children to conditions, RAs began conducting daily 15 minute instruction sessions in patterning, literacy, or mathematics with the children assigned to each condition. Sessions were counterbalanced, and resulted in a total of 45 minutes of instruction per classroom per day.

\subsubsection{Patterning Intervention}

The children assigned to the patterning intervention were taught by the RAs via a binder of printed patterns. There were 190 patterns, five of each type that was represented in the patterning test. RAs used play with dinosaur or pony toys to engage the children, coax an answer from them, or teach them the correct answer to the question: which item comes next? All teaching patterns were missing the item in last position in the pattern, and presented four items from which the child was to select the one which would complete the pattern. The correct option was equally often in the first, second, third, or fourth position.

\subsubsection{Literacy Intervention}

The literacy intervention started with letter bags containing items that started with a consonant sound. Children dumped all items out of two letter bags, then sorted them into the correct bag by determining with which letter the object started. For example, the A letter bag might have pictures of an ant, a plastic apple, a drawing of an arm, etc. while the B letter bag might have a ball, a picture of a boy, a small boat, etc. After mastering single-letter bags, children followed the same process with bags for letter blends, such as "bl" or "wr." After completing the letter blend bags, children in the literacy group interacted with end sound flash cards, where there is one end sound, such as "ing," and multiple possible beginning sound options to create a word using that end sound.

After children mastered basic phonological understandings through the letter bags, letter blend bags, and flash cards, they worked with short children's poems. Poems focused on a specific phonetic ending (i.e. -ay, -ing, -est). RAs began the reading session by talking with students for one minute to practice basic conversation skills and oral vocabulary. Then, children began the intervention session by rereading the poem read during the previous session, and were given as much help as necessary, with the goal of increasing fluency, teaching decoding, and exploring comprehension strategies. RAs followed the reading of the familiar poem with questions about the contents of the poem, such as "Where did the owl live?" to facilitate comprehension. After reading the familiar poem, children began with reading a new poem and a discussion of that poem. On the first day of interacting with a new poem, RAs read the poem aloud and asked the children 
about what they heard in the poem to aid reading comprehension. On the second day, children read along with the RA to target fluency. On the third and last day, children read the poems independently and the RA facilitated discussion via questions to target comprehension and vocabulary. The RA ended the 15 -minute reading intervention by summarizing what was done that day with the children.

\subsubsection{Mathematics Intervention}

Mathematics activities focused on developing skills for counting, adding or subtracting, identifying and interacting with shapes, solving oral story problems, and solving math problems related to money. Materials used included small manipulatives (i.e. cubes, small balls, apples), activity cards, coins, and activity pages. Each activity began with an overview of the skill being covered in the task, at which point the RA could choose to use the "back up" or "go ahead" options for each activity to make the task easier or harder for the children based on their current skill level. All activities included a concluding question or task that addressed the goal skill of the activity.

An example of an Adding/Subtracting activity is one called "Roll it up!" Children rolled two dice with numbers on them, rather than dots, and added the numbers together. Children could also use one die with numbers and one with dots and use the dots to practice counting onward from the number rolled. If this was too difficult, children could "back up" to use both dice with dots and count the dots to practice adding the two together. If this was too easy, children could use one die numbered to six and one higher numbered die and add these larger numbers together.

The intervention was yoked based on the patterning group, and continued for 8 - 12 weeks, depending upon when the child taught patterning learned all of the patterns. When a child in the patterning group had mastered all of the teaching patterns included in the intervention, instruction for that child and the most advanced child in the literacy and math groups was finished. By ending the intervention for children in trios, with one math and literacy child stopping intervention at the same time as the patterning child who had mastered that instruction, the number of sessions across groups remained equivalent.

At the end of the school year (May-June), blind assessors conducted the posttests for each child in the intervention. The two-part patterning posttest was administered in two 10 - 15 minute sessions. The Key Math 3 Diagnostic Assessment was administered in one $10-15$ minute session. The DIBELS and TOWRE were given in one 10 - 15-minute session. Testing sessions were split over the course of at least 4 days for each child so that no child completed more than one 10 - 15 minute session of testing in one day.

\section{Results}

The children taught patterning outscored the others on patterning, $\mathrm{F}(2.36)=$ $8.507, p<.001$, partial eta squared $=.32$, as shown in Table 1 . Bonferroni tests 
yielded $p<.001$ for the comparison of patterning scores for the patterning group with those of the literacy group, and $p<.01$ for the comparison between the patterning group and the mathematics group. No other differences approached significance. The patterning children's patterning scores were $36 \%$ higher than those of the children taught literacy, and $27 \%$ higher than those of the children taught mathematics.

The absolute values of the scores for the patterning group were somewhat higher than those for the other groups on the TOWRE Sight Words Efficiency and Phonemic Decoding Efficiency scales, but all were at the first grade, fourth month level for words and first grade, sixth month level for the phonemes. As can be seen in Table 1, the mathematics and patterning groups made similar scores on the DIBELS scales, and those of the literacy group were lower in an absolute sense, but the differences were trivial and the power for these comparisons was very low (partial eta squared $=.016$ ). All groups were at or above benchmark (28) for the spring of kindergarten on the Nonsense Word Fluency scale. Means and SD are given in Table 2.

The children taught mathematics made the highest scores in an absolute sense on the KEY math Algebra scale, scoring 29\% - 36\% higher than the other groups. Their raw scores were grade equivalents of the fifth month of kindergarten, whereas the scores of the patterning and literacy groups were at the second month. However, the differences were trivial statistically, and power for comparisons was very low (partial eta squared $=.064$ ).

Table 1. Analysis of differences in patterning.

\begin{tabular}{ccccccc}
\hline Source & Sum of Squares & df & Mean Square & F & $p$ & Partial Eta Squared \\
\hline Intercept & 9016.641 & 1 & 9016.641 & 922.156 & .000 & .962 \\
Condition & 166.359 & 2 & 83.179 & 8.507 & .001 & .321 \\
Error & 352.000 & 36 & 9.778 & & & \\
\hline
\end{tabular}

Table 2. Descriptive statistics for patterning, literacy, and mathematics measures.

\begin{tabular}{ccccccc}
\hline & Mathematics Instruction & Literacy & Instruction & Patterning Instruction \\
\hline & Mean & SD & Mean & SD & Mean & SD \\
\hline DIBELS & & & & & & \\
Initial Sounds Correct & 14.77 & 1.59 & 12.62 & 4.13 & 14.31 & 1.89 \\
Time for Initial Sounds & 38.54 & 13.40 & 48.92 & 26.28 & 37.08 & 12.92 \\
Correct Letter Names & 47.50 & 14.80 & 46.15 & 12.00 & 52.15 & 18.14 \\
Correct Letter Sounds & 43.33 & 25.98 & 37.46 & 25.63 & 39.08 & 31.44 \\
Words Read Correctly & 11.92 & 10.05 & 8.85 & 9.29 & 10.77 & 11.89 \\
TOWRE & & & & & & 19.16 \\
Sight Word Efficiency & 21.62 & 15.95 & 18.92 & 17.70 & 23.69 & 8.20 \\
Phoneme Decoding & 8.08 & 6.55 & 6.38 & 5.56 & 8.38 & 1.42 \\
KEYmath Algebra & 5.77 & 3.14 & 4.46 & 3.15 & 4.23 & 18.08 \\
Patterning & 14.23 & 2.20 & 13.31 & 2.81 & & 4.07 \\
\hline
\end{tabular}


Patterning scores correlated with the TOWRE Sight Word scale, $r(36)=.299$, $p=.032$, and approached significance with the DIBELS Nonsense Word Fluency scale, $r(36)=.270, p=.051$ (see Table 3 ). The correlation coefficient is the effect size; these fall in the $.10-.30$ small to medium range, according to Cohen's (1992) rubric.

\section{Discussion}

The patterning instruction clearly was effective, as the children taught pattering outscored those taught either mathematics or early literacy on the patterning test, even though groups were small and the conservative Bonferroni correction was applied. However, as in the experiment by Shriver et al. (2017), there was no demonstrable effect of the patterning instruction on early literacy or mathematics.

It is noteworthy that not only was the patterning group not superior to the literacy group on mathematics, but there was also no correlation between the patterning scores of all 39 children and their KEYmath algebra scores. The theoretical arguments advanced by numerous educators (Baroody, 1993, Clements \& Sarama, 2007a, 2007b, 2007c; Papic, 2007, Papic et al., 2011; Warren, Cooper, \& Lamb, 2006 and others) have indicated that there should be a relation between patterning and (pre)algebra for young children. However, these theorists were speaking of simple alternating patterns, not complex patterns such as those used here and with first graders.

The empirical research published previously (c.f. reviews by Burgoyne et al., 2017; Pasnak, 2017) has consistently shown relations between the patterning and mathematics scores of both preschoolers and first graders on a variety of mathematics measures, whether the patterns were simple alternations or complex like those used in the present research. However, this experiment and that of Shriver et al. (2017) are the only ones conducted with kindergartners, and neither shows such a relationship. The difference could be a function of the mathematics measures used, but Shriver et al. (2017) used Woodcock-Johnson III scales 10,18A, and 18B, which did show such relationships for first grade children (Kidd et al., 2013; Kidd et al., 2014; Pasnak et al., 2015) and the KEYmath Algebra scale used present experiment also showed relations for first graders. The relevant limitation of the experiment by Shriver et al. is the time (spring) that most of the intervention was conducted, which may not have left time for it to affect the children's subsequent mathematics achievement. That does not apply to the present research. However, the power of the present intervention was very low, as the subject pool shrank from 64 to 39, and that may account for the lack of an effect. It is possible, however, that there is actually no relation between mathematics and mastery of complex patterns by kindergartners, as no hint of a correlation was found,- the $r$ obtained is close to zero-and 39 subjects is not too few to show an effect if one exists.

Although the intervention did not improve literacy scores, there were correlations between some literacy measures and patterning scores. Such relations have 
Table 3. Correlations between variables.

\begin{tabular}{|c|c|c|c|c|c|c|c|c|}
\hline & $\mathrm{T}$ & $\mathrm{LN}$ & LS & WR & SW & $\mathrm{Ph}$ & $\mathrm{A}$ & $\mathrm{Pa}$ \\
\hline Initial Sounds (IS) & $-.70^{* *}$ & $.46^{* *}$ & $.42^{\star *}$ & $.41^{* *}$ & $.34^{*}$ & $.32^{\star}$ & .24 & .24 \\
\hline Time $(\mathrm{T})$ & & $-.44^{* *}$ & $-.48^{\star *}$ & $-.51^{\star *}$ & $-.43^{* *}$ & $-.50^{\star *}$ & $-.28^{\star}$ & -.25 \\
\hline Letter Names (LN) & & & $.47^{\star *}$ & $.56^{* *}$ & $.64^{\star *}$ & $.67^{* *}$ & $.28^{*}$ & .22 \\
\hline Letter Sounds (LS) & & & & $.91^{* *}$ & $.76^{\star *}$ & $.80^{* *}$ & $.51^{\star *}$ & .18 \\
\hline Words Read (WR) & & & & & $.83^{\star *}$ & $.84^{\star *}$ & $.49^{* *}$ & .27 \\
\hline Sight Words (SW) & & & & & & $.89^{* *}$ & $.51^{* *}$ & $.30^{*}$ \\
\hline Phoneme (Ph) & & & & & & & $.46^{* *}$ & .21 \\
\hline Algebra (A) & & & & & & & & .02 \\
\hline
\end{tabular}

${ }^{* *} p<.05{ }^{* *} p<.01$.

been reported previously for first graders, both as a result of interventions (Hendricks et al., 2006; Kidd et al., 2013; Kidd et al., 2014; Pasnak et al., 2015; Shriver et al., 2017) and in the absence of any intervention (Bock et al., 2015; Pasnak et al., 2016, Schmerold et al., 2017). The correlation between the patterning scores for these kindergartners and the TOWRE SWEscale is similar to that between this scale and complex patterns reported for first-graders (Pasnak et al., 2016). It appears that Clements et al. (2004) and Fox (2005) were correct in their suggestions that patterning is related to early literacy. The question is whether a patterning intervention will improve literacy. The answer is clearly yes for first graders if complex patterns are taught to them in the fall, but the answer for kindergartners is not so clear. While Shriver found an effect on one DIBELS scale-Initial Sounds-the present research does not show any effect on that same scale.

\section{Conclusion and Limitations}

It is clear that the present study was underpowered. Power efficiency coefficients were quite low. Although the kindergartners did show more understanding of complex patterns, direct instruction in mathematics and literacy did not have significant effects. The effect of understanding patterns would be indirect. The improved abstract thinking that patterning instruction is thought to impart could help children to better understand the teacher's lesson plans and classroom instruction. However, it is not likely that such an indirect effect would be detected when the effects of direct instruction were not. As Pasnak et al. (2015) pointed out, the potential benefit of patterning instruction is that it could benefit children in both literacy and mathematics. There are already plenty of teaching methods that benefit children in one or the other of these arenas (but not both).

A second limitation is that there was substantial subject attrition, and with relatively few subjects the randomization may have failed. The low scores of the literacy children on the literacy scales suggest that this may have occurred, even though the deficit is not statistically significant. 
A third limitation concerns the sample characteristics. Pasnak, Hansbarger, Hart, Dodson, \& Blaha (1996) reported an instance in which the same intervention conducted simultaneously in two schools worked very well in one but very poorly in the other, a discrepancy the researchers attributed to sample differences. The sample in the present case clearly contained many children from economically disadvantaged families, most of them from other cultures. (Nearly three-quarters of the children were eligible for free or reduced lunches; $78 \%$ were identified as having minority ethnicities, and the $22 \%$ reported as white were mainly Middle Eastern, although the percentage for that particular ethnicity is unavailable.) Clements and Sarama (2011) report substantial differences in patterning for disadvantaged children. Hence, the fruits of a patterning intervention might be different for a different sample.

In sum, the instruction avoided the pitfalls of the only other patterning intervention conducted with kindergartners (Shriver et al. 2017) in that instruction was conducted for seven months beginning in the early Fall, and the patterning measure was appropriate for the patterns taught. It produced an effect on patterning scores but had no demonstrable effect on mathematics or literacy scores. However, it does not conclusively demonstrate that kindergartners cannot profit academically from patterning instruction, primarily because of the small sample size, and possibly because of the nature of the sample.

\section{Funding}

The research reported here was supported by the Institute of Education Sciences, US Department of Education, through Grant 305A170114 to George Mason University. The opinions expressed are those of the authors and do not represent views of the Institute or the US Department of Education.

\section{Conflicts of Interest}

The authors declare no conflicts of interest regarding the publication of this paper.

\section{References}

Baroody, A. J. (1993). Problem Solving, Reasoning, and Communicating (K-8): Helping Kids Think Mathematically. New York: Macmillan.

Bock, A., Cartwright, K., Gonzalez, C., O’Brien, S., Robinson, M. F., Schmerold, K., Shriver, A., \& Pasnak, R. (2015). The Role of Cognitive Flexibility in Pattern Understanding. Journal of Education and Human Development, 4, 19-25. https://doi.org/10.15640/jehd.v4n1a3

Burgoyne, K., Witteveen, K., Tolan, A., Malone, S., \& Hulme, C. (2017). Pattern Understanding: Relationships with Arithmetic and Reading Development. Child Development Perspectives, 11, 239-244. https://doi.org/10.1111/cdep.12240

Clements, D. H., \& Samara, J. (2007c). Early Childhood Mathematics Learning. In F. K. Lester Jr. (Ed.), Second Handbook on Mathematics Teaching and Learning (pp. 461-555). Charlotte, NC: Information Age. 
Clements, D. H., \& Sarama, J. (2007a). Mathematics. In R. S. New, \& M. Cochran (Eds.), Early Childhood Education: An International Encyclopedia (Vol. 2, pp. 502-509). Westport, CN: Praeger.

Clements, D. H., \& Sarama, J. (2007b). Curriculum, Mathematics. In R. S. New, \& M. Cochran (Eds.), Early Childhood Education: An International Encyclopedia (Vol. 1, pp. 193-198). Westport, CN: Praeger.

Clements, D. H., Sarama, J., \& Dibiase, A. (2004). Engaging Young Children in Mathematics: Standards for Early Childhood Mathematics Education. Mahweh, NJ: Erlbaum. https://doi.org/10.4324/9781410609236

Cohen, J. (1992). A Power Primer. Psychological Bulletin, 112, 155-159. https://doi.org/10.1037/0033-2909.112.1.155

Ducolon, C. K. (2000). Quality Literature as a Springboard to Problem Solving. Teaching Children Mathematics, 6, 442-446.

Economopoulos, K. (1998). What Comes Next? The Mathematics of Patterning in Kindergarten. Teaching Children Mathematics, 5, 230-233.

http://www.jstor/stable/41197171?seq=1\#page_scan_tab_contents

Fox, J. (2005). Child-Initiated Mathematical Patterning in the Pre-Compulsory Years. International Group for the Psychology of Mathematics Education, 2, 313-320. http://eprints.que.edu.au.archive/0004247

Hendricks, C., Trueblood, L., \& Pasnak, R. (2006). Effects of Teaching Patterning to First Graders. Journal of Research on Childhood Education, 21, 79-89. https://doi.org/10.1080/02568540609594580

Herman, M. L. (1973). Patterning before Mathematics in Kindergarten. Dissertation Abstracts International, 33, 4060.

Jarboe, T., \& Sadler, S. (2003). It's as Easy as 1,2,3: Patterns and Activities for a Creative, Balanced Mathematics Program. Peterborough, NJ: Crystal Springs Books.

Kidd, J. K., Carlson, A. G., Gadzichowski, K. M., Boyer, C. E., Gallington, D. A., \& Pasnak, R. (2013). Effects of Patterning Instruction on the Academic Achievement of First Grade Children. Journal of Research in Childhood Education, 27, 224-238. https://doi.org/10.1080/02568543.2013.766664

Kidd, J. K., Pasnak, R., Gadzichowski, K. M., Gallington, D. A., McKnight, P. E., Boyer, C. E., \& Carlson, A. (2014). Instructing First-Grade Children on Patterning Improves Reading and Mathematics. Early Education and Development, 25, 134-151. https://doi.org/10.1080/10409289.2013.794448

McGarvey, L. M. (2012). What Is a Pattern? Criteria Used by Teachers and Young Children. Mathematical Thinking and Learning, 14, 310-337. https://doi.org/10.1080/10986065.2012.717380

Mulligan, J. Mitchelmore, M., Kemp, C., Marston, J., \& Highfield, K. (2008). Encouraging Mathematical Thinking through Pattern and Structure: An Intervention in the First Year of Schooling. Australian Primary Mathematics Classroom, 13, 10-15. http://www.aamt.edu.au/

National Association for the Education of Young Children/National Council of Teachers of Mathematics Education (2010/2014). Early Childhood Mathematics: Promoting Good Beginnings. Washington DC: NYAEC. http://www.state.nj.us/education/ece/pd/math/naeyc_nctm.pdf

National Council of Teachers of Mathematics (1993). Principles and Standards for School Mathematics. Reston, VA: NCTM. http://www.nctm.org/Standards-and-xPositions/PrinciplesandStandards/Algebra 
National Mathematics Advisory Panel (2008). Foundations for Success: The Final Report of the National Mathematics Advisory Panel. Washington DC: US Department of Education.

Papic, M. (2007). Promoting Repeating Patterns with Young Children-More than Just Alternating Colors. Australian Primary Mathematics Classroom, 12, 8-13.

Papic, M. M., Mulligan, J. T., \& Mitchelmore, M. C. (2011). Assessing the Development of Preschoolers' Mathematical Thinking. Journal for Research for Mathematics Education, 42, 237-269. https://doi.org/10.5951/jresematheduc.42.3.0237

http://www.aare.edu.au/data/publications/2012/Mulligan12.pdf

Pasnak, R. (2017). Empirical Studies of Patterning. Psychology, 8, 2276-2293. https://doi.org/10.4236/psych.2017.813144

Pasnak, R., Hansbarger, A., Dodson, S., Hart, J., \& Blaha, J. (1996). Differential Results of Instruction at the Preoperational-Concrete Operational Transition. Psychology in the Schools, 33, 70-83.

Pasnak, R., Kidd, J. K., Gadzichowski, K. M., Gallington, D. A, Schmerold, K. L., \& West, H. M. (2015). Abstracting Sequences: Reasoning that Is a Key to Academic Achievement. Journal of Genetic Psychology, 176, 171-193. https://doi.org/10.1080/00221325.2015.1024198

Pasnak, R., Schmerold, K. L., Robinson, M. F., Gadzichowski, K. M., Bock, A. M., O’Brien, S. E., Kidd, J. K., \&. Gallington, D. A. (2016) Understanding Number Sequences Leads to Understanding Number Concepts. The Journal of Educational Research, 109, 640-646. https://doi.org/10.1080/00220671.2015.1020911

Rittle-Johnson, B., Fyfe, E. R., Hofer, K. G., \& Farran, D. C. (2017). Early Math Trajectories: Low-Income Children's Mathematics Knowledge from Ages 4 to 11. Child Development, 88, 1727-1742. https://doi.org/10.1111/cdev.12662

Rittle-Johnson, B., Hofer, K., Fyfe, M. R., \& Farren, D. C. (2015). It's a Pattern! The Importance of Early Pattern Knowledge for Middle School Mathematics Achievement. Philadelphia, PA: The Biennial Conference of the Society for Research in Child Development.

Sarama, J., \& Clements, D. H. (2004). Building Blocks for Early Childhood Mathematics. Early Childhood Research Quarterly, 19, 181-189.

Scandura, J. (1971). Mathematics: Concrete Behavioral Foundations. New York: Harper \& Rowe.

Shriver, A., Lauderdale, L., Yassa, M., Schroeder, E., Chen, E., Schabinger, E., Righi, M., \& Pasnak, R. (2017). The Effects of in-Class Tutoring of Kindergarteners on Patterning, Reading, or Mathematics. Journal of Education and Human Development, 6, 1-6. https://doi.org/10.15640/jehd.v6n1a1

Threlfall, J. (1999). Repeating Patterns in the Early Primary Years. In A. Orton (Ed.), Patterns in the Teaching and Learning of Mathematics (pp. 18-30). London: Cassell.

Warren, E. A., Cooper, T. J., \& Lamb, J. T. (2006). Investigating Functional Thinking Is the Elementary Classroom: Foundations of Early Algebraic Reasoning. The Journal of Mathematics Behavior, 25, 208-223. https://doi.org/10.1016/j.jmathb.2006.09.006 